\title{
Improved glucose regulation in type 2 diabetic patients with DPP-4 inhibitors: focus on alpha and beta cell function and lipid metabolism
}

\author{
Bo Ahrén ${ }^{1}$ - James E. Foley ${ }^{2}$
}

Received: 2 November 2015 / Accepted: 22 January 2016 /Published online: 19 February 2016

(C) Springer-Verlag Berlin Heidelberg 2016

\begin{abstract}
Inhibition of dipeptidyl peptidase-4 (DPP-4) is an established glucose-lowering strategy for the management of type 2 diabetes mellitus. DPP-4 inhibitors reduce both fasting and postprandial plasma glucose levels, resulting in reduced $\mathrm{HbA}_{1 \mathrm{c}}$ with low risk for hypoglycaemia and weight gain. They act primarily by preventing inactivation of the incretin hormones glucose-dependent insulinotropic polypeptide and glucagon-like peptide-1, thereby prolonging the enhanced endogenous levels of these hormones after meal ingestion. This in turn causes islet and extrapancreatic effects, including increased glucose sensing in islet alpha and beta cells. These effects result in increased insulin secretion and decreased glucagon secretion being more effective in hyperglycaemic states and reduced insulin secretion and increased glucagon secretion being more effective during hypoglycaemia. Other secondary pharmacological actions of DPP-4 inhibitors include mobilisation and burning of fat during meals, decrease in fat extraction from the gut, reduction of fasting lipolysis and liver fat and increase in LDL particle size. These actions contribute to the clinical effects of DPP-4 inhibition, and the reduced demand for insulin could also lead to a durability benefit. This review summarises the current knowledge of the secondary pharmacological actions of DPP-4 inhibitors that lead to improved glucose regulation in patients with type 2 diabetes, focusing on alpha and beta cell function and lipid metabolism.
\end{abstract}

Bo Ahrén

Bo.Ahren@med.lu.se

1 Faculty of Medicine, Department of Clinical Sciences Lund, Lund University, B11 BMC, Sölvegatan 19, 22184 Lund, Sweden

2 World Wide Medical Affairs, Novartis Pharmaceuticals Corporation, East Hanover, NJ, USA
Keywords Dipeptidyl peptidase-4 inhibitors · GIP · GLP-1 · Glucagon · Insulin · Review

$\begin{array}{ll}\text { Abbreviations } \\ \text { Apo B-48 } & \text { Apolipoprotein B-48 } \\ \text { CV } & \text { Cardiovascular } \\ \text { DPP-4 } & \text { Dipeptidyl peptidase-4 } \\ \text { FPG } & \text { Fasting plasma glucose } \\ \text { GIP } & \text { Glucose-dependent insulinotropic polypeptide } \\ \text { GLP-1 } & \text { Glucagon-like peptide-1 } \\ \text { HGP } & \text { Hepatic glucose production } \\ \text { IFG } & \text { Impaired fasting glucose } \\ \text { ISR } & \text { Insulin secretory rate } \\ \text { Rd } & \text { Rate of disappearance of glucose } \\ \mathrm{Si} & \text { Sensitivity index }\end{array}$

\section{Introduction}

Islet dysfunction is a prerequisite for the development of type 2 diabetes mellitus and is characterised by inadequate insulin secretion in the face of increased demand for insulin in combination with augmented glucagon secretion in spite of hyperglycaemia [1]. The inadequate insulin secretion is caused by reduced sensitivity of the beta cells to glucose and a progressive decrease in insulin secretion capacity [2-5]; the augmented glucagon secretion is caused by its impaired suppression by glucose [6]. The reduced sensitivity of beta cells to glucose appears mainly to manifest itself in susceptible individuals with an inherently lower capacity for insulin secretion subsequent to increased demand for insulin because of greater triacylglycerol storage in non-fat tissues, termed lipotoxicity [4]. The demand for insulin is increased further by reduced glucose sensitivity in alpha cells, resulting in inappropriately 
elevated glucagon levels and, eventually, glucotoxicity through increased fasting plasma glucose (FPG) [7]. The capacity for insulin secretion then diminishes over time [1]. Type 2 diabetes is also associated with diminished glucagon counter-regulation in the face of hypoglycaemia [8]. These combined islet defects result in fasting and postprandial hyperglycaemia because of increased hepatic glucose production (HGP) and impaired glucose utilisation together with defective ability to counteract hypoglycaemia. Therefore, islet defects render type 2 diabetes a disorder in which there is deficient glucose regulation during both hyperglycaemia and hypoglycaemia. Hence, islet dysfunction is an important target for correcting glucose abnormalities in type 2 diabetes.

Until the advent of dipeptidyl peptidase-4 (DPP-4) inhibitors, there were no oral antihyperglycaemic agents for management of these multiple underlying pathologies. The initial premise for using DPP-4 inhibition as a glucose-lowering strategy was based on the effects of glucagon-like peptide1 (GLP-1), and the potential of this treatment in type 2 diabetes was first reported in 1992 [9]. A few years later, it was demonstrated that GLP-1 is inactivated by DPP-4, suggesting that inhibition of DPP-4 may extend and enhance the physiological effects of GLP-1 [10]. This triggered the search for DPP-4 inhibitors that could be used therapeutically $[11,12]$. A proof-of-concept study demonstrating improved glycaemia by DPP-4 inhibition in type 2 diabetes was published in 2002 [13] and the first DPP-4 inhibitor entered the market in 2006. Since then, at least five DPP-4 inhibitors have been licensed for the treatment of type 2 diabetes; they are all well tolerated, efficacious and easy to use [14]. These DPP-4 inhibitors differ in their chemical structures, metabolic pathways, pharmacokinetics and interactions with the DPP-4 catalytic site [14]. However, they all prevent the inactivation of GLP-1 and glucose-dependent insulinotropic polypeptide (GIP), prolonging meal-induced increases in the active forms of these two incretin hormones. We consider this to be the primary pharmacological action of the DPP-4 inhibitor class. The prolongation of meal-induced increases in GLP-1 and GIP in turn results in pancreatic and extrapancreatic effects, which we characterise as secondary pharmacological actions of DPP-4 inhibitors, which in turn results in the clinical benefits of reduced glycaemia without increased risk for hypoglycaemia or weight gain.

Here we review the secondary pharmacological actions of DPP-4 inhibitors on alpha and beta cell function and on lipid metabolism that lead to improved glucose regulation in patients with type 2 diabetes. We have not considered all potential benefits (e.g. on bone or immune function) nor have we addressed potential adverse effects of DPP-4 inhibitors, since these aspects have been covered in previous reviews [15-18]. Instead, our focus is to highlight the mechanism studies in humans that explain the clinical benefits of DPP-4 inhibitors.

\section{Search strategy}

We conducted a systematic search in PubMed using all synonyms of DPP-4 inhibitors and filtered all English-language journal articles restricted to human studies up until 10 June 2015. This comprised of a pool of 3,302 articles. First, from this pool, all articles having the keywords 'vildagliptin', 'sitagliptin', 'saxagliptin', 'alogliptin' or 'linagliptin' and 'patients', 'individuals' or 'subjects' in either the title or text of the abstract were shortlisted $(\mathrm{N} 1=878)$. Second, from the pool, all articles having the keywords 'vildagliptin', 'sitagliptin', 'saxagliptin', 'alogliptin' or 'linagliptin' and 'study' in either the title or text of the abstract were shortlisted in parallel $(\mathrm{N} 2=659)$. Duplicates were removed $(\mathrm{N}=512)$ and the abstracts of the 1,025 resulting articles were then screened manually for relevance to beta cells, alpha cells and extrapancreatic effects on lipid metabolism secondary to prolongation of the meal-induced increases in GLP-1 and GIP (references to articles are not cited; this information is available from the authors on request). We did not consider papers that reported only homeostasis model assessment of beta cell function and homeostasis model assessment insulin resistance as measures of beta cell function and insulin resistance since the number of relevant papers would greatly exceed the allowed number of references in this review.

\section{Effects on beta cells}

Analysis of insulin or C-peptide levels after ingestion of glucose or a mixed meal is one of the most common methods used to explore the effects of DPP-4 inhibitors on beta cells. In such studies, however, the data need to be adjusted for the prevailing glucose levels because it is the relationship between insulin secretion and glucose concentration that is the most basic reflection of beta cell function and not the actual levels of insulin or C-peptide. When analyses were adjusted accordingly, all DPP-4 inhibitors were shown to increase in insulin and C-peptide relative to glucose levels after oral glucose or mixed-meal administration [19-25]. Some studies in which an insulinogenic index has been calculated (insulin or C-peptide level divided by glucose level) have shown that DPP-4 inhibitors do indeed increase beta cell function [13, 22, 26-29]. Nevertheless, the extent of this stimulation is difficult to establish because glucose levels are reduced by DPP-4 inhibition. Instead, beta cell function is better assessed after i.v. administration of glucose. Improvements in acute insulin response to glucose given by the i.v. route have been seen in individuals with impaired fasting glucose (IFG) following treatment with vildagliptin [30], but not sitagliptin [31], and in patients with type 2 diabetes following treatment with vildagliptin and sitagliptin [26, 32-35]. This suggests that DPP-4 inhibitors can improve beta cell function both within 
and outside the context of meal ingestion. In line with this, vildagliptin and sitagliptin improved insulin secretion in response to stimulation with glucose given orally and intravenously; paradoxically no change in the incretin effect was observed [33, 35].

An even more appropriate estimation of beta cell function is provided by calculating the insulin secretory rate (ISR). This is performed by deconvolution of C-peptide levels (C-peptide is co-secreted with insulin and has linear clearance that is easily estimated) and the AUC for ISR or glucose (insulin secretion relative to glucose $[\mathrm{ISR} / \mathrm{G}]$ ) can then be used as an index of beta cell function. This index was consistently found to be increased after a mixed meal in vildagliptin-treated individuals who had impaired glucose tolerance [36], IFG [30] or type 2 diabetes and who received vildagliptin as monotherapy, either acutely [37] or after 2 years [38], or who received vildagliptin as add-on to metformin [39] or sulfonylureas [40]. It is reasonable to assume that other DPP-4 inhibitors have the same effect. Furthermore, after a single dose of vildagliptin was given to patients with type 2 diabetes before their evening meal, ISR/G was increased significantly throughout the entire overnight post-absorptive period [37]. In these patients the effect was the same during the evening meal as before breakfast, suggesting that the raised ISR/G was not due to the increase in GLP-1 levels beyond those seen at the beginning of meals physiologically, but rather due to an extension of the physiological effect over the entire overnight period [37].

Another measure for estimating insulin secretion is to calculate the ratio of the incremental AUC for C-peptide to the AUC for glucose during standard meal tests. Using this index in a study of vildagliptin in metformin-treated patients with inadequate glycaemic control, insulin secretion was found to be increased by $>30 \%$ after 12 weeks of vildagliptin treatment, and this was sustained throughout 1 year of treatment [19]. In another study, beta cell function assessed as ISR/G during meal tests was sustained over 2 years with vildagliptin in patients with type 2 diabetes and mild hyperglycaemia, but not in the placebo comparator group [38]. Improved beta cell function also appeared to be maintained over a 2 year period with sitagliptin plus metformin treatment [41].

The relationship between insulin secretion and glucose concentrations includes the two components of sensitivity and capacity (Fig. 1). A more complete measure of beta cell function therefore is needed to analyse both these components. The sensitivity of insulin secretion to glucose is a particularly important measure since it is an early indicator of defect in beta cell function in type 2 diabetes. This measure can be estimated by the Mari model which estimates the ISR at different glucose levels and therefore provides the full-range sensitivity of glucose to stimulate insulin secretion [42-44]. When this model was applied to data from a study in drugnaive patients with type 2 diabetes and mild hyperglycaemia, vildagliptin increased glucose sensitivity of insulin secretion

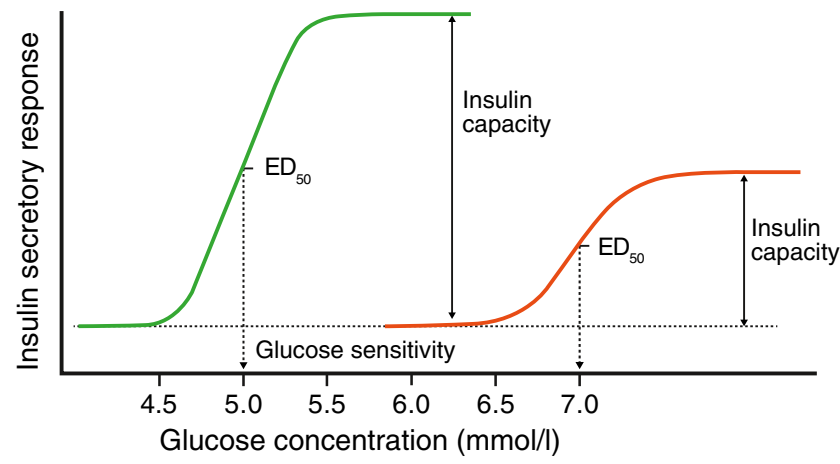

Fig. 1 Schematic illustration of the relationship between insulin secretion and glucose concentration. Glucose sensitivity reflects the relationship between insulin secretion and glucose concentration and is quantified by the $\mathrm{ED}_{50}$ (glucose concentration eliciting $50 \%$ of maximal insulin secretion [insulin capacity]). The two curves represent the relationship under normal conditions (left) and in type 2 diabetes mellitus (right), illustrating that type 2 diabetes is characterised by reduced glucose sensitivity (increased $\mathrm{ED}_{50}$ ) and reduced insulin capacity

but did not influence the glucose-insensitive stimulation of insulin secretion [42, 43]. Hence, according to this model, DPP-4 inhibitors seem to augment beta cell function mainly by increasing glucose sensitivity, with a glucose threshold of approximately $6 \mathrm{mmol} / \mathrm{l}$. This has also been demonstrated in studies where a single dose of vildagliptin or sitagliptin increased plasma insulin levels when given before a $75 \mathrm{~g}$ OGTT in patients with type 2 diabetes [20,23]; no such effect was found in healthy volunteers with an FPG of $\approx 4.5 \mathrm{mmol} / 1$ [45] or in individuals with IFG with an FPG of $\approx 5.5 \mathrm{mmol} / 1$ [31] (i.e. below the glucose threshold). These findings were extended by studies showing that sitagliptin improved beta cell glucose sensitivity during both a mixed meal and i.v. administration of isoglycaemic glucose in patients with type 2 diabetes $[33,46]$. This implies, as has been shown with chronic sitagliptin or vildagliptin therapy, that DPP-4 inhibition specifically improves glucose sensing in beta cells regardless of the stimulus; this in turn may explain why there is no change in the incretin effect, which is calculated as the ratio of insulin secretion after oral vs i.v. administration of glucose at matching glucose levels $[33,35]$. A most interesting observation made in patients on insulin therapy was that an improved glucose sensing was observed with sitagliptin, when evaluated by the C-peptide minimum model [21, 47], suggesting that DPP-4 inhibition increases glucose sensitivity of insulin secretion in patients on insulin therapy. Similarly, in a 16 week study in individuals with recent-onset type 2 diabetes, using the Mari model showed that a combination of alogliptin with pioglitazone increased the glucose sensing of insulin secretion whereas alogliptin as monotherapy had no effect on beta cell function [48]. Whether the finding that alogliptin alone did not increase beta cell glucose sensitivity in this study compared with the effects of other DPP-4 inhibitors in other studies reflects different effects of the different inhibitors remains to be explored in head-to-head studies. This result would 
however suggest that thiazolidinediones may enhance the beta cell action of DPP-4 inhibition, which is an interesting observation requiring further study.

Beta cell function can also be measured by the total capacity to secrete insulin [49]. This may be related to beta cell mass, which is reduced in animal models of type 2 diabetes. GLP-1 and DPP-4 inhibition increase beta cell mass via increased beta cell neogenesis and decreased beta cell apoptosis when determined in models of diabetes using young animals, whereas this effect is not seen in more mature animals [50]. This suggests that treatment does not increase beta cell mass in older animals. Support comes from human data on the capacity of beta cells to stimulate insulin secretion as studied after combined glucose and arginine-stimulated C-peptide secretion rate. Thus, whereas there indeed was an increase in the capacity for insulin secretion after 3 or 12 months of treatment with vildagliptin $[5,32]$ or sitagliptin [34] as long as treatment was ongoing, such an effect was not maintained after a 3 month washout period. Similarly, a pilot study failed to show any evidence that sitagliptin preserved beta cell function after intensive insulin therapy [51]. These results together indicate that DPP-4 inhibition has no disease-modifying effect on beta cells up to at least 2 years of therapy and that the improved beta cell function is evident only as long as the inhibitor stimulates beta cell function. This failure is perhaps the greatest unrealised early promise of the GLP-1-based therapies. Although these data suggest that DPP-4 inhibition does not appear to restore beta cell mass, they are consistent with its maintenance of beta cell functional mass, possibly due to the long-term influence of GLP-1 in association with reduced glycaemia and relieved glucotoxicity.

It is thus clear that DPP-4 inhibition stimulates insulin secretion in a glucose-dependent manner by increasing the glucose sensitivity of beta cells. This infers that the inhibition of insulin secretion is augmented when glucose levels fall to hypoglycaemic levels. This concept was examined in a study in drug-naive individuals with type 2 diabetes [52]. It was found that the inhibition of insulin secretion, as estimated by modelling of C-peptide data, was indeed augmented by vildagliptin when glucose levels were reduced to $2.5 \mathrm{mmol} / 1$ by means of a hyperinsulinaemic-hypoglycaemic clamp. This suggests that DPP-4 inhibition increases glucose sensitivity in beta cells over a large range of glucose levels, from hypoglycaemic to hyperglycaemic levels. As a consequence this would allow beta cells to adapt to the degree of insulin resistance, contributing to improved fasting and postprandial glycaemia $[20,22,35]$ and the rapid increase or decrease in insulin secretion according to need enables the beta cells to show a better response to the next hyperglycaemic challenge. By extending the recovery time after a reduction in circulating glucose, allowing proinsulin to split into insulin and C-peptide due to improved proinsulin processing, DPP-4 inhibitors decrease the overall insulin exposure and the proinsulin-toinsulin ratio $[20,28,53,54]$.

\section{Effects on alpha cells}

Inhibition of glucagon secretion is an important target in the treatment of type 2 diabetes because hyperglucagonaemia contributes to both fasting and postprandial hyperglycaemia $[55,56]$. It is therefore of great interest that DPP-4 inhibitors inhibit glucagon secretion in individuals with type 2 diabetes [11]. This was initially demonstrated in 2004 when vildagliptin was shown to inhibit the glucagon response to a mixed meal [56] and was later confirmed for vildagliptin, sitagliptin, saxagliptin and alogliptin in several studies $[20,30,37,42$, $46,48,57-60]$. DPP-4 inhibition has also been found to suppress the inappropriate glucagon response to oral glucose in patients with type 2 diabetes $[20,23,25,35]$. One study demonstrated that the ability of insulin to reduce glucagon after meals was augmented by vildagliptin [59], thus revealing the additive glucagonostatic effects of insulin and DPP-4 inhibition. Another study showed that saxagliptin reduced the mealinduced increase in glucagon levels obtained by the sodiumglucose transport protein-2 inhibitor dapagliflozin [61]. In contrast, DPP-4 inhibition seems to have no effect on glucagon levels either in healthy individuals with a mean FPG of approximately $4.5 \mathrm{mmol} / \mathrm{l}$ [45] or in individuals with IFG and a mean FPG of approximately $6.0 \mathrm{mmol} / 1$ [31]. This shows a clear glucose-dependent mechanism for the inhibitory action of DPP-4 inhibition on glucagon secretion. A long-term study with vildagliptin as add-on to metformin treatment found that postprandial glucagon levels were still reduced after 2 years [62], demonstrating that the glucagonostatic effect of DPP-4 inhibition persists over time.

The inhibitory effect of DPP-4 inhibition on glucagon secretion is most likely explained by GLP-1, which is known to inhibit glucagon secretion in patients with type 2 diabetes [9]. The inhibitory effect of GLP-1 on glucagon secretion was found to be glucose dependent $[63,64]$ and this has been explained by increased sensitivity of glucose to inhibit glucagon secretion [6]. However, it is unlikely that GLP-1 has a direct effect on alpha cells, as GLP-1 receptors on pancreatic alpha cells are scarce or nonexistent [11]. Instead, secondary mechanisms may explain how GLP-1 mediates the inhibition of glucagon secretion by DPP-4 inhibition. One such mechanism may involve increased intra-islet insulin concentrations since GLP-1 increases insulin secretion and insulin inhibits glucagon secretion [65]. To examine this possibility, insulinopenic patients with type 1 diabetes have been studied based on the assumption that: if DPP-4 inhibition reduces glucagon by increasing intra-islet insulin, there would be no glucagonostatic effect in such patients. However, several studies have shown that indeed GLP-1 or DPP-4 inhibition reduces glucagon levels also in type 1 diabetes. Thus, in 1992 GLP-1 was shown to inhibit glucagon secretion in type 1 diabetes [9], and DPP-4 inhibition was found to suppress inappropriate glucagon secretion during mixed meals in type 
1 diabetes to the same extent as seen in patients with type 2 diabetes $[11,66,67]$. This indicates that the suppression of inappropriate glucagon secretion by DPP-4 inhibition is not secondary to increased insulin secretion. An animal study has suggested that the glucagonostatic effect of GLP-1 is mediated by a local paracrine effect of somatostatin, stimulated by GLP1 , acting on the somatostatin receptor subtype 2 on alpha cells [68]. Studies on the detailed mechanism in humans remain to be performed.

In contrast to the suppressive effect of DPP-4 inhibitors on inappropriate glucagon secretion in response to glucose or mixed meals in type 2 diabetes, DPP-4 inhibition does not inhibit the glucagon counter-regulation to hypoglycaemia. On the contrary, one study in drug-naive individuals with type 2 diabetes demonstrated that DPP-4 inhibition by vildagliptin enhances alpha cell responsiveness to the stimulatory effect of hypoglycaemia [52], and sustained glucagon counterregulation to hypoglycaemia has been shown for vildagliptin in insulin-treated patients with type 2 diabetes [69] and in patients with type 1 diabetes [67]. This demonstrates that DPP-4 inhibition has a dual effect on glucagon secretion such that when glucose levels are elevated glucagon levels are reduced whereas during hypoglycaemia glucagon levels are increased [11]. There are several mechanisms that may explain the counter-regulatory glucagon response to hypoglycaemia, as illustrated in Fig. 2. While it is known that hypoglycaemia per se reduces intra-islet insulin levels, adrenaline (epinephrine) released from the adrenal glands and autonomic nerves may contribute to glucagon counter-regulation. A

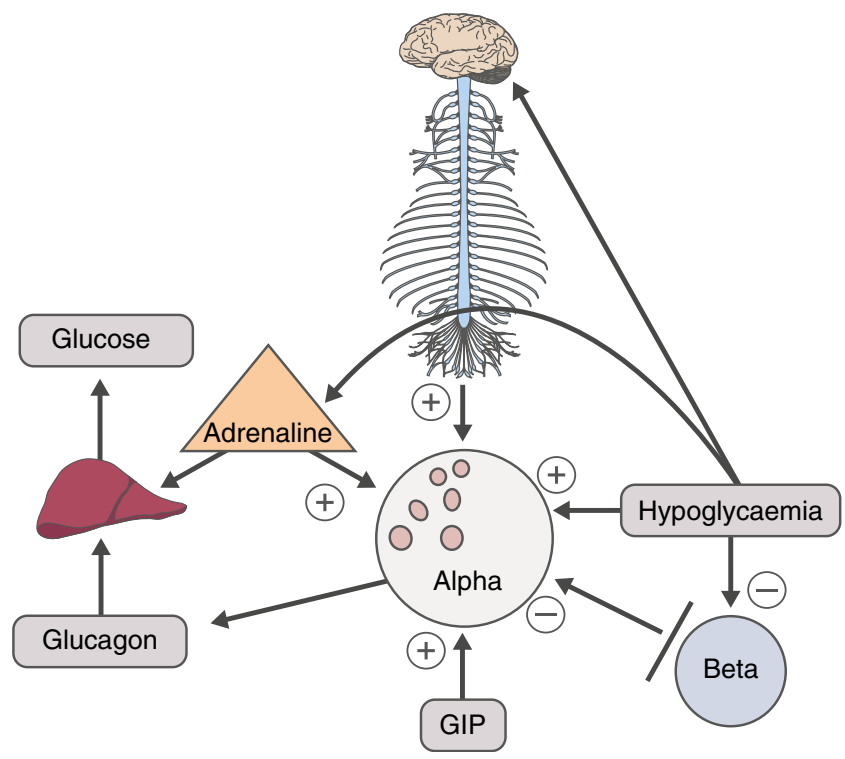

Fig. 2 Five main mechanisms underlying stimulation of glucagon secretion by alpha cells during hypoglycaemia: reduced beta cell secretion elicits a reduction in intra-islet insulin-dependent inhibition of glucagon secretion; direct effect of low glucose; activation of the autonomic nerves; stimulated release of adrenaline from the adrenals and action of GIP. The released glucagon and adrenaline then stimulate HGP resulting in the glucose counter-regulation potential additional mechanism for DPP-4 inhibition may be the incretin hormone GIP, which is known to stimulate glucagon release during euglycaemia [64] or hypoglycaemia [70], whereas it does not seem to affect glucagon secretion at elevated glucose levels. Hence, GIP has an effect on glucagon secretion that is in contrast to the effect of GLP-1. This suggests that the increase in GIP levels by DPP-4 inhibition may be the mechanism by which glucagon counter-regulation to hypoglycaemia is sustained or augmented by these drugs. Support for this comes from animal studies showing that mice with genetic deletion of the GIP receptors have a poorer glucagon counter-regulation to hypoglycaemia during vildagliptin treatment compared with normal mice with intact GIP receptors [71]. Therefore, although the reduction of glucagon during hyperglycaemia seems to be mediated by GLP-1, stimulation by DPP-4 inhibition of glucagon secretion during hypoglycaemia may be mediated by GIP. Together this suggests an important dual effect of DPP-4 inhibition on glucagon secretion mediated by both GLP-1 and GIP (illustrated in Fig. 3). Other factors may, however, also contribute: neural influences have been demonstrated in a study on sitagliptin in mice [72] and, furthermore, HGP is not only governed by the absolute portal glucagon levels but also by the portal glucagon: insulin ratio [73].

The dual effect that DPP-4 inhibition exerts on glucagon secretion may be of clinical importance. First, the GLP-1mediated reduction in glucagon at elevated glucose levels may result in reduced HGP. This is supported by reports of a reduced postprandial HGP, associated with reduced glucagon levels, after treatment with vildagliptin [37] and also after sitagliptin in combination with metformin, although in the latter study sitagliptin alone had no effect [74]. In contrast, during euglycaemic-hyperinsulinaemic clamp after an overnight fast, when glucagon most likely is not alerted,

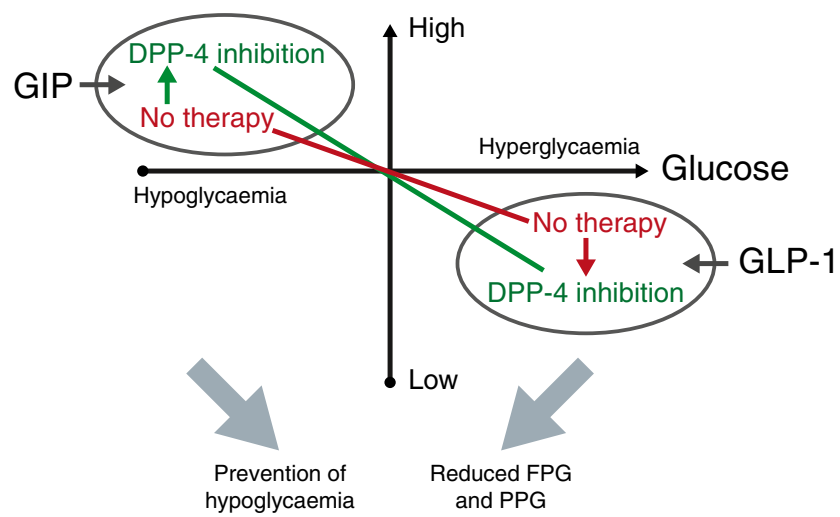

Fig. 3 Relationship between circulating glucose ( $x$-axis: from hypoglycaemia through euglycaemia to hyperglycaemia) and glucagon secretion ( $y$-axis from low to high levels) under normal conditions and during DPP-4 inhibition. DPP-4 inhibition reduces glucagon secretion at high glucose levels (through GLP-1) and augments glucagon secretion at low glucose levels (through GIP). These effects result in reduced FPG and postprandial plasma glucose (PPG) and prevention of hypoglycaemia 
vildagliptin was found not to affect HGP in patients with type 2 diabetes [75]. The importance of the reduction in glucagon for the glycaemic effect of DPP-4 inhibition is also supported by the significant correlation between reduction of postprandial glucagon and postprandial glucose after treatment with vildagliptin in type 2 diabetes [56].

Second, the improved counter-regulation may contribute to the low risk for hypoglycaemia during treatment with DPP-4 inhibitors particularly if the DPP-4 inhibition is combined with insulin, due to sustained glucagon secretion [76]. Taken together, the dual effects of DPP-4 inhibition on glucagon secretion contribute to two of the main effects of this treatment-lowering of hyperglycaemia and protection from hypoglycaemia.

\section{Intra-islet effects}

There is accumulating evidence that DPP-4 is expressed in the pancreatic islets and in humans the expression seems mainly to be localised to alpha cells [77]. Also GLP-1 is expressed in islet alpha cells [78]. It is therefore possible that DPP-4 inhibition acts locally in the islets to protect the intra-islet inactivation of GLP-1, resulting in improved islet function, although there is a potential conflict in reported data since DPP-4 activity has been shown to positively correlate with insulin secretion in human islets [79]. Nevertheless, there is a possibility that DPP-4 inhibition may improve islet function through a local action to prevent local production of GLP-1. Support for this comes from studies showing that vildagliptin significantly potentiates glucose-stimulated insulin secretion in human islets [79] and that linagliptin improves beta cell function, provides protection against glucotoxicity, lipotoxicity and cytokine toxicity and stabilises active GLP-1 secreted from human islets [80].

\section{Extrapancreatic effects on lipid metabolism}

Vildagliptin has been shown to increase postprandial lipolysis in adipose tissue and increase postprandial fat oxidation in muscle, suggesting that the fat accumulated in adipocytes during fasting is mobilised and burned in muscle in the fed state during DPP-4 inhibition [81]. Furthermore, postprandial triacylglycerol-rich lipoprotein levels are reduced by DPP-4 inhibition with vildagliptin, sitagliptin and alogliptin [82-84]. A reduction in total serum triacylglycerol and chylomicrons was observed, reflecting reductions in chylomicron apolipoprotein B-48 (Apo B-48) and chylomicron cholesterol. The effect on Apo B-48 was later shown not to be due to improved glucose control with sitagliptin [85]. More recently it was shown that a single oral dose of sitagliptin reduces the production of intestinally derived Apo B-48-containing lipoprotein particles in healthy men [86]. Furthermore, fractional clearance of particles of both intestinal and hepatic origin and production of particles of hepatic origin were not affected. As chylomicrons are the initial lipoproteins into which dietary triacylglycerols are packaged, these findings suggest that DPP-4 inhibitors may have an inhibitory effect on fat absorption from the gut [87]. The effect of DPP-4 inhibitors on Apo B-48 production is probably mediated by GLP-1 receptors, as similar findings have been reported with a GLP-1 receptor agonist [88]. Further analysis of the original vildagliptin study demonstrated a decrease in postprandial remnant-like particle triacylglycerols and remnant-like particle cholesterol in type 2 diabetes, with a concomitant increase in LDL particle-size therapy, suggesting that GLP-1-based therapies may have unique mechanisms of relevance for cardiovascular (CV) risk [89].

In contrast to the effect vildagliptin has of mobilising fat during meals, vildagliptin was found to decrease the rate of fasting lipolysis as indicated by a reduction in palmitate flux [58]. As vildagliptin does not increase fasting insulin levels and as, in animal studies, both GLP-1 and GIP inhibit lipolysis, it is likely that this effect of vildagliptin is a direct incretin hormone-mediated extrapancreatic effect [11]. An inappropriate rate of fasting lipolysis is the major cause of elevated liver triacylglycerol concentrations; a reduction in lipolysis is thus expected to decrease liver triacylglycerol levels [90]. A substantial reduction in fasting liver triacylglycerol levels almost to levels of the non-diabetic control group was observed in a recently reported study with vildagliptin; this decrease was not due to the relationship between change in body weight and liver fat [75].

\section{Integrating the secondary pharmacological effects with the clinical benefits of DPP-4 inhibitors}

Beyond the primary pharmacology of preventing inactivation of GLP-1 and GIP to prolong their increased levels after meal ingestion, DPP-4 inhibition results in a number of secondary pharmacological effects, which are both pancreatic and extrapancreatic (Fig. 4). These effects result in reduction of postprandial plasma glucose and FPG levels, leading to reduced $\mathrm{HbA}_{1 \mathrm{c}}$ levels, with no increase in the risk for hypoglycaemia or weight gain. Increasing insulin secretion and decreasing glucagon secretion more effectively in hyperglycaemic states are likely the primary benefits of this class of drug, and the effects of GLP-1 on alpha and beta cells appear to be equally important for its glucose-lowering action [64]. An important effect of GLP-1 receptor agonists is a direct action on the brain stem to induce satiety and inhibit gastric emptying [59]. A variety of methods have been used to assess appetite and gastric emptying directly, including rate of ingested glucose into the circulation, surrogates of appetite 
Fig. 4 The pharmacology of DPP-4 inhibitors is divided into primary pharmacology, which prevents the inactivation of GLP1 and GIP, which prolongs the increase in active incretin hormones after meal ingestion, and secondary pharmacology, which involves several mechanisms in islets, liver, fat tissue, muscle and gut. The mechanisms involved in the secondary pharmacology explain the clinical effects seen during treatment with DPP-4 inhibitors

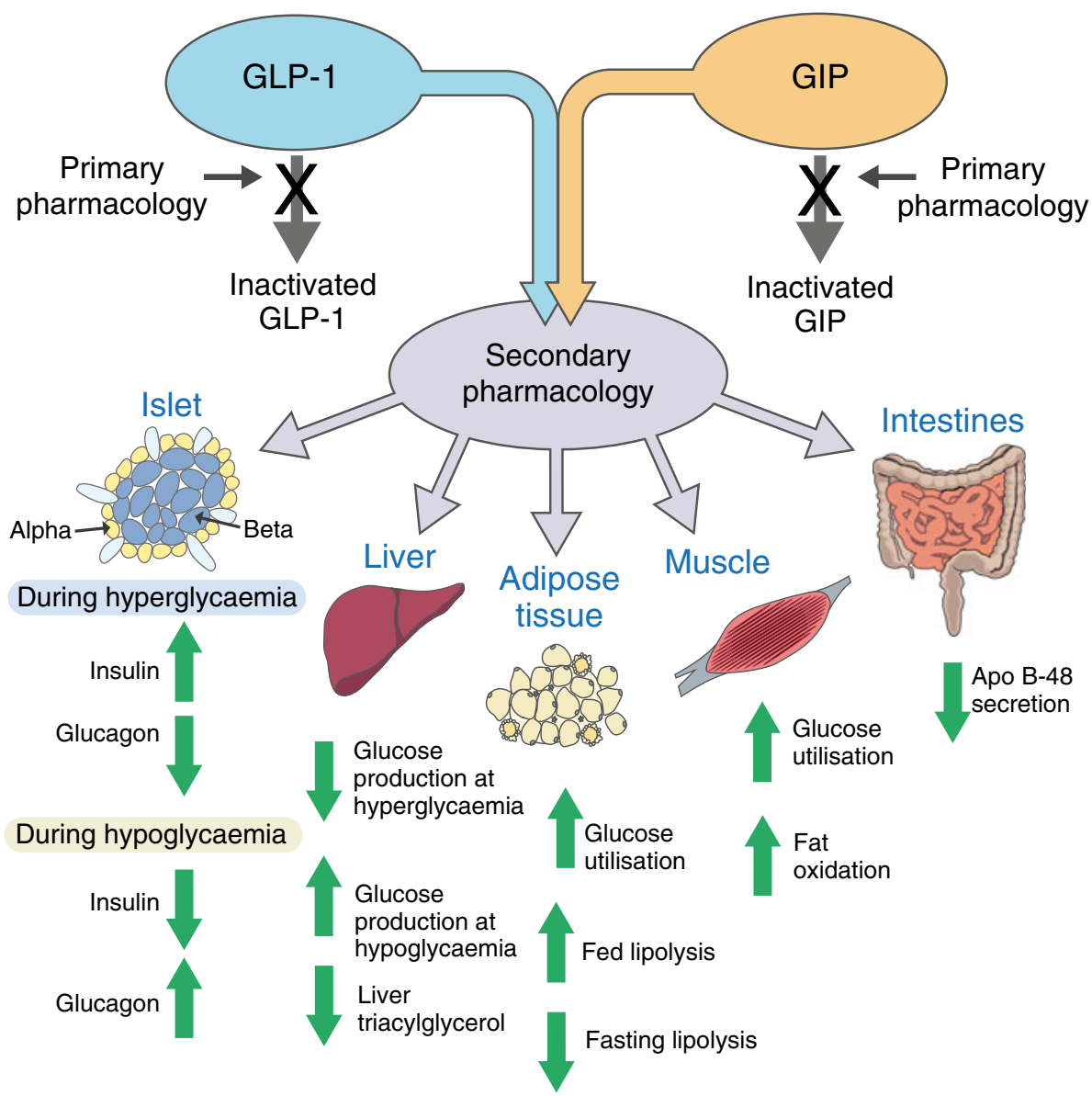

such as ghrelin and gastrin levels or the paracetamol test of gastric emptying and findings indicate that DPP-4 inhibitors have no effect on satiety and gastric emptying [59, 60, 91-95]. The prevailing evidence suggests that the effect of GLP-1 on satiety and gastric emptying requires doses of GLP-1 that are much higher than those achieved by DPP-4 inhibition [94]. Conversely, the reduced insulin secretion and increased glucagon levels in hypoglycaemia brought about by DPP-4 inhibition lead to better counter-regulation. This largely explains the low potential for hypoglycaemia by this class of drugs.

The effects of DPP-4 inhibitors on lipid metabolism all predict reduced $\mathrm{CV}$ risk. For instance, inhibiting lipolysis in the fasting state over many weeks should redistribute fat storage from non-fat tissues to the fat cells; the observation that there is reduced liver fat is consistent with this mechanism. On the other hand, mobilising and burning fat during meals avoids the accumulation of fat that could otherwise lead to weight gain and consequent $\mathrm{CV}$ risk. Furthermore, the reduced Apo B-48 level is consistent with reduced CV risk. However, despite reduced hyperglycaemia without increased hypoglycaemia as well as the improved lipid profile there has been no evidence of reduced CV risk when DPP-4 inhibitors have been added to other therapy in patients with type 2 diabetes and established $\mathrm{CV}$ risk over a median period of 3 years, as demonstrated for sitagliptin [96]. Of course it is possible that a primary prevention trial of longer duration might result in a CV benefit due to the beneficial effects on glycaemia and lipids.

As discussed in the introduction, insulin resistance can be due to glucose toxicity, due to inappropriately elevated glucagon levels and to lipotoxicity. Vildagliptin, sitagliptin and saxagliptin all improve a dynamic marker of insulin sensitivity, the oral glucose insulin sensitivity index (OGIS) [19, 24, $25,46]$, likely due to a combination of reduced glucagon, reduced lipotoxicity and reduced glucotoxicity. The sensitivity index $(\mathrm{Si})$ from an oral minimum model does not include the glucagon component and it is not predicted to have a lipotoxicity component after short duration. Inexplicably, after 9 days of vildagliptin treatment in patients with type 2 diabetes, there was no improvement in Si [54], whereas after 2 weeks there was a clear improvement in the $\mathrm{Si}$ in individuals with IFG [30].

There are a number of studies of DPP-4 inhibitors in which glucose utilisation has been assessed by a euglycaemichyperinsulinaemic clamp; the insulin concentrations used in these studies preclude any contribution of glucagon during the clamp. Glycogen storage was presumed to be the rate-limiting step in all of these clamp studies, except in one in which the 
duration was more than twice that of the others [58]. This study revealed final insulin concentrations that were twice those found in the other clamp studies in which glucose utilisation in muscle was the presumed rate-limiting step [97]. We recalculated the data presented in that paper and found that the amount of glucose utilised during the clamp exceeded the amount of glycogen that could be stored. Since any glucose that cannot be oxidised or stored as glycogen must be converted to fat, we presume that lipogenesis is the rate-limiting step under this condition. Vildagliptin increased glucose utilisation in this clamp where thus we presume lipogenesis is the rate-limiting step.

Sitagliptin and vildagliptin also increased glucose utilisation in clamps where glucose utilisation in muscle was predicted to be the rate-limiting step [46, 98-100]. In contrast, vildagliptin did not increase glucose utilisation in two other clamp studies where glucose utilisation in muscle was predicted to be the rate-limiting step $[5,75]$. Participants in both of these studies had lower baseline FPG values than the participants in any of the other studies, suggesting that the degree of glucotoxicity is a confounding variable in the response to a DPP-4 inhibitor [75]. In one of these studies, where there was no effect on glucose utilisation during the clamp, there was no change in fasting HGP, while FPG was reduced [75]; thus it follows that the fasting rate of disappearance of glucose (Rd) increased. The lack of effect on the clamp is not consistent with increased glycogen storage in muscle, suggesting that there could be increased lipogenesis. There was also a $25 \%$ reduction in liver fat [75].

Of course, increased lipogenesis would increase liver fat [101]; thus this hypothesis presumes that the reduction in lipolysis leading to reduced liver fat outweighs the increase in lipogenesis leading to increased liver fat. We believe this hypothesis merits further discussion and investigation.

The low hypoglycaemic potential of DPP-4 inhibitors prevents the weight gain associated with defensive eating to avoid hypoglycaemia. Thus, DPP-4 inhibitors do not lead to weight gain despite the caloric penalty associated with reducing glucose levels from above to below the renal threshold [102]. Although data is lacking for any direct mechanism that can explain this weight mitigation, one potential mechanism is the mobilisation and burning of fat during meals and another is the reduction in Apo B-48 secretion leading to decreased fat extraction from the gut. In contrast to GLP-1 receptor agonists, there is no satiety effect with DPP-4 inhibitors [91].

The lingering question is: are all of the secondary pharmacological effects presented here DPP-4 class effects? Some are clearly class effects as demonstrated by their being seen with more than one DPP-4 inhibitor. Some of these effects are only seen with one DPP-4 inhibitor and determining whether they are class effects awaits further studies. However, it is difficult to imagine why any of the meal-related effects would not be class effects. Therefore, DPP-4 inhibitors take advantage of both GLP-1 and GIP for their secondary pharmacology, which is mainly directed toward improvement of islet function. Since this class of drugs improve both beta and alpha cell dysfunction during both hyper- and hypoglycaemia, it represents the first class of drugs to target all of the combined manifestations of islet dysfunction in type 2 diabetes.

Acknowledgements The authors thank B. Pasagada of Novartis Healthcare Pvt. Ltd. for technical help with the submission of manuscript.

\section{Compliance with ethical standards}

Funding This data search was funded by Novartis Pharma AG. The study sponsor was not involved in the design of the study; the collection, analysis, and interpretation of data; writing the report; or the decision to submit the report for publication.

Duality of interest BA has consulted for Novartis, GlaxoSmithKline, Merck, Sanofi, Novo Nordisk, Boehringer Ingelheim and Takeda, and has received lecture fees from Novartis, Merck, Novo Nordisk and Sanofi, all of which manufacture DPP-4 inhibitors or GLP-1 receptor agonists. JEF is employed by and own shares in Novartis Pharmaceuticals Corporation.

Contribution statement JEF designed the search strategy and conducted the abstract screening, analysis and interpretation. BA analysed and interpreted the screened articles. Both the authors had full access to all data and take responsibility for the integrity of the data and accuracy of analyses. Both the authors drafted the manuscript, read and approved the final draft.

\section{References}

1. Kahn SE, Cooper ME, Del Prato S (2014) Pathophysiology and treatment of type 2 diabetes: perspectives on the past, present, and future. Lancet 383:1068-1083

2. Davidson MB (1985) Pathogenesis of impaired glucose tolerance and type II diabetes mellitus - current status. West J Med 142: 219-229

3. Turner RC, Holman RR (1976) Insulin rather than glucose homoeostasis in the pathophysiology of diabetes. Lancet 1 : 1272-1274

4. DeFronzo RA (2010) Insulin resistance, lipotoxicity, type 2 diabetes and atherosclerosis: the missing links. The Claude Bernard Lecture 2009. Diabetologia 53:1270-1287

5. Foley JE, Bunck MC, Möller-Goede DL et al (2011) Beta cell function following 1 year vildagliptin or placebo treatment and after 12 week washout in drug-naive patients with type 2 diabetes and mild hyperglycaemia: a randomised controlled trial. Diabetologia 54:1985-1991

6. Dunning BE, Foley JE, Ahrén B (2005) Alpha cell function in health and disease: influence of glucagon-like peptide-1. Diabetologia 48:1700-1713

7. Del Prato S (2009) Role of glucotoxicity and lipotoxicity in the pathophysiology of type 2 diabetes mellitus and emerging treatment strategies. Diabet Med 26:1185-1192

8. Bolli GB, Tsalikian E, Haymond MW, Cryer P, Gerich JE (1984) Defective glucose counterregulation after subcutaneous insulin in noninsulin-dependent diabetes mellitus. J Clin Invest 73:15321541 
9. Gutnaik M, Ørskov C, Holst JJ, Ahrén B, Efendić S (1992) Antidiabetic effect of glucagon-like peptide-1 (7-36) amide in normal subjects and patients with diabetes mellitus. $\mathrm{N}$ Engl $\mathrm{J}$ Med 326:1316-1322

10. Deacon CF, Johnsen AH, Holst JJ (1995) Degradation of glucagon-like peptide-l by human plasma in vitro yields an $\mathrm{N}$ terminally truncated peptide that is a major endogenous metabolite in vivo. J Clin Endocrinol Metab 80:952-957

11. Ahrén B, Schweizer A, Dejager S, Villhauer EB, Dunning BE, Foley JE (2011) Mechanisms of action of the dipeptidyl peptidase-4 inhibitor vildagliptin in humans. Diabetes Obes Metab 13:775-783

12. Thornberry NA, Weber AE (2007) Discovery of JANUVIA (sitagliptin), a selective dipeptidyl peptidase IV inhibitor for the treatment of type 2 diabetes. Curr Top Med Chem 7:557-568

13. Ahrén B, Simonsson E, Larsson H et al (2002) Inhibition of dipeptidyl peptidase IV improves metabolic control over a 4week study period in type 2 diabetes. Diabetes Care 25:869-875

14. Scheen AJ (2015) A review of gliptins for 2014. Exp Opin Pharmacother 16:43-62

15. Tella SH, Rendell MS (2015) DPP-4 inhibitors: focus on safety. Exp Opin Drug Saf 14:127-140

16. Aroor A, McKarns S, Nistala R et al (2013) DPP-4 inhibitors as therapeutic modulators of immune cell function and associated cardiovascular and renal insulin resistance in obesity and diabetes. Cardiorenal Med 3:48-56

17. Ceccarelli E, Guarino EG, Meriotti D et al (2013) Beyond glycemic control in diabetes mellitus: effects of incretin-based therapies on bone metabolism. Front Endocrinol 4:73

18. Hocher B, Reichetzeder C, Alter ML (2012) Renal and cardiac effects of DPP4 inhibitors - from preclinical development to clinical research. Kidney Blood Press Res 36:65-84

19. Ahrén B, Pacini G, Foley JE, Schweizer A (2005) Improved mealrelated $\beta$-cell function and insulin sensitivity by the dipeptidyl peptidase-IV inhibitor vildagliptin in metformin-treated patients with type 2 diabetes over 1 year. Diabetes Care 28:1936-1940

20. He YL, Wang Y, Bullock JM et al (2007) Pharmacodynamics of vildagliptin in patients with type 2 diabetes during OGTT. J Clin Pharmacol 47:633-641

21. Wu T, Ma J, Bound MJ et al (2014) Effects of sitagliptin on glycemia, incretin hormones, and antropyloroduodenal motility in response to intraduodenal glucose infusion in healthy lean and obese humans and patients with type 2 diabetes treated with or without metformin. Diabetes 63:2776-2787

22. Williams-Herman D, Johnson J, Teng R et al (2010) Efficacy and safety of sitagliptin and metformin as initial combination therapy and as monotherapy over 2 years in patients with type 2 diabetes. Diabetes Obes Metab 12:442-451

23. Herman GA, Bergman A, Stevens C et al (2006) Effect of single oral doses of sitagliptin, a dipeptidyl peptidase-4 inhibitor, on incretin and plasma glucose levels after an oral glucose tolerance test in patients with type 2 diabetes. J Clin Endocrinol Metab 91: 4612-4619

24. Rosenstock J, Aguilar-Salinas C, Klein E et al (2009) Effect of saxagliptin monotherapy in treatment-naïve patients with type 2 diabetes. Curr Med Res Opin 25:2401-2411

25. DeFronzo RA, Hissa MN, Garber AJ et al (2009) The efficacy and safety of saxagliptin when added to metformin therapy in patients with inadequately controlled type 2 diabetes with metformin alone. Diabetes Care 32:1649-1655

26. Pratley RE, Schweizer A, Rosenstock J et al (2008) Robust improvements in fasting and prandial measures of $\beta$-cell function with vildagliptin in drug-naïve patients: analysis of pooled vildagliptin monotherapy database. Diabetes Obes Metab 10: 931-938
27. Wu YJ, Guo X, Li CJ et al (2015) Dipeptidyl peptidase-4 inhibitor, vildagliptin, inhibits pancreatic beta cell apoptosis in association with its effects suppressing endoplasmic reticulum stress in $\mathrm{db} / \mathrm{db}$ mice. Metabolism 64:226-235

28. Yoon KH, Shockey GR, Teng R et al (2011) Effect of initial combination therapy with sitagliptin, a dipeptidyl peptidase-4 inhibitor, and pioglitazone on glycemic control and measures of $\beta$ cell function in patients with type 2 diabetes. Int J Clin Pract 65: 154-164

29. Sjöstrand M, Iqbal N, Lu J, Hirshberg B (2014) Saxagliptin improves glycemic control by modulating postprandial glucagon and C-peptide levels in Chinese patients with type 2 diabetes. Diabetes Res Clin Pract 105:185-191

30. Utzschneider KM, Tong J, Montgomery B et al (2008) The dipeptidyl peptidase-4 inhibitor vildagliptin improves $\beta$-cell function and insulin sensitivity in subjects with impaired fasting glucose. Diabetes Care 31:108-113

31. Bock G, Dalla Man C, Micheletto F et al (2010) The effect of DPP-4 inhibition with sitagliptin on incretin secretion and on fasting and postprandial glucose turnover in subjects with impaired fasting glucose. Clin Endocrinol 73:189-196

32. D'Alessio DA, Denney AM, Hermiller LM et al (2009) Treatment with the dipeptidyl peptidase-4 inhibitor vildagliptin improves fasting islet-cell function in subjects with type 2 diabetes. $\mathrm{J}$ Clin Endocrinol Metab 94:81-88

33. Vardarli I, Nauck MA, Köthe LD et al (2011) Inhibition of DPP-4 with vildagliptin improved insulin secretion in response to oral as well as "isoglycemic" intravenous glucose without numerically changing the incretin effect in patients with type 2 diabetes. J Clin Endocrinol Metab 96:945-954

34. Aaboe K, Knop FK, Vilsbøll T et al (2010) Twelve weeks treatment with the DPP-4 inhibitor, sitagliptin, prevents degradation of peptide YY and improves glucose and non-glucose induced insulin secretion in patients with type 2 diabetes mellitus. Diabetes Obes Metab 12:323-333

35. Vardarli I, Arndt E, Deacon CF, Holst JJ, Nauck MA (2014) Effects of sitagliptin and metformin treatment on incretin hormone and insulin secretory responses to oral and "isoglycemic" intravenous glucose. Diabetes 63:663-674

36. Rosenstock J, Foley JE, Rendell M et al (2008) Effects of the dipeptidyl peptidase-IV inhibitor vildagliptin on incretin hormones, islet function, and postprandial glycemia in subjects with impaired glucose tolerance. Diabetes Care 31:30-35

37. Balas B, Baig MR, Watson C et al (2007) The dipeptidyl peptidase IV inhibitor vildagliptin suppresses endogenous glucose production and enhances islet function after single-dose administration in type 2 diabetic patients. J Clin Endocrinol Metab 92:1249-1255

38. Scherbaum WA, Schweizer A, Mari A et al (2008) Evidence that vildagliptin attenuates deterioration of glycaemic control during 2 year treatment of patients with type 2 diabetes and mild hyperglycaemia. Diabetes Obes Metab 10:1114-1124

39. Bosi E, Camisasca RP, Collober C, Rochotte E, Garber AJ (2007) Effects of vildagliptin on glucose control over 24 weeks in patients with type 2 diabetes inadequately controlled with metformin. Diabetes Care 30:890-895

40. Garber AJ, Foley JE, Banerji MA et al (2008) Effects of vildagliptin on glucose control in patients with type 2 diabetes inadequately controlled with a sulphonylurea. Diabetes Obes Metab 10:1047-1056

41. Williams-Herman D, Xu L, Teng R et al (2012) Effect of initial combination therapy with sitagliptin and metformin on $\beta$-cell function in patients with type 2 diabetes. Diabetes Obes Metab 14:67-76

42. Mari A, Sallas WM, He YL et al (2005) Vildagliptin, a dipeptidyl peptidase-IV inhibitor, improves model-assessed $\beta$-cell function 
in patients with type 2 diabetes. J Clin Endocrinol Metab 90: 4888-4894

43. Mari A, Scherbaum WA, Nilsson PM et al (2008) Characterization of the influence of vildagliptin on model-assessed -cell function in patients with type 2 diabetes and mild hyperglycemia. J Clin Endocrinol Metab 93:103-109

44. Ferrannini E, Mari A (2014) $\beta$-Cell function in type 2 diabetes. Metabolism 63:1217-1227

45. El-Ouaghlidi A, Rehring E, Holst JJ et al (2007) The dipeptidyl peptidase 4 inhibitor vildagliptin does not accentuate glibenclamide-induced hypoglycemia but reduces glucoseinduced glucagon-like peptide 1 and gastric inhibitory polypeptide secretion. J Clin Endocrinol Metab 92:4165-4171

46. Muscelli E, Casolaro A, Gastaldelli A et al (2012) Mechanisms for the antihyperglycemic effect of sitagliptin in patients with type 2 diabetes. J Clin Endocrinol Metab 97:2818-2826

47. Vilsbøll T, Rosenstock J, Yki-Järvinen $\mathrm{H}$ et al (2010) Efficacy and safety of sitagliptin when added to insulin therapy in patients with type 2 diabetes. Diabetes Obes Metab 12:167-177

48. van Raalte DH, van Genugten RE, Eliasson B et al (2014) The effect of alogliptin and pioglitazone combination on various aspects of $\beta$-cell function in patients with recent-onset type 2 diabetes. Eur J Endocrinol 170:565-574

49. Kahn SE, Carr DB, Faulenbach MV, Utzschneider KM (2008) An examination of $\beta$-cell function measures and their potential use for estimating beta-cell mass. Diabetes Obes Metab 10(Suppl 4):63-76

50. Omar BA, Vikman J, Sörhede Winzell M et al (2013) Enhanced beta cell function and anti-inflammatory effect after chronic treatment with the dipeptidyl peptidase 4 inhibitor vildagliptin in an advanced age diet induced obesity mouse model. Diabetologia 56 : $1752-1760$

51. Retnakaran R, Qi Y, Opsteen C, Vivero E, Zinman B (2010) Initial short-term intensive insulin therapy as a strategy for evaluating the preservation of beta-cell function with oral antidiabetic medications: a pilot study with sitagliptin. Diabetes Obes Metab 12:909915

52. Ahrén B, Schweizer A, Dejager S et al (2009) Vildagliptin enhances islet responsiveness to both hyper- and hypoglycemia in patients with type 2 diabetes. J Clin Endocrinol Metab 94:12361243

53. Brazg R, Xu L, Dalla Man C, Cobelli C, Thomas K, Stein PP (2007) Effect of adding sitagliptin, a dipeptidyl peptidase-4 inhibitor, to metformin on 24-h glycaemic control and beta-cell function in patients with type 2 diabetes. Diabetes Obes Metab 9:186193

54. Del Prato S, Barnett AH, Huisman H, Neubacher D, Woerle HJ, Dugi KA (2011) Effect of linagliptin monotherapy on glycaemic control and markers of $\beta$-cell function in patients with inadequately controlled type 2 diabetes: a randomized controlled trial. Diabetes Obes Metab 13:258-267

55. Ahrén B (2015) Glucagon - early breakthroughs and recent discoveries. Peptides 67:74-81

56. Ahrén B, Landin-Olsson M, Jansson PA, Svensson M, Holmes D, Schweizer A (2004) Inhibition of dipeptidyl peptidase-4 reduces glycemia, sustains insulin levels, and reduces glucagon levels in type 2 diabetes. J Clin Endocrinol Metab 89:2078-2084

57. Vella A, Bock G, Giesler PD et al (2007) Effects of dipeptidyl peptidase-4 inhibition on gastrointestinal function, meal appearance, and glucose metabolism in type 2 diabetes. Diabetes 56: $1475-1480$

58. Azuma K, Rádiková Z, Mancino J et al (2008) Measurements of islet function and glucose metabolism with the dipeptidyl peptidase 4 inhibitor vildagliptin in patients with type 2 diabetes. J Clin Endocrinol Metab 93:459-464

59. Man CD, Bock G, Giesler PD et al (2009) Dipeptidyl peptidase-4 inhibition by vildagliptin and the effect on insulin secretion and action in response to meal ingestion in type 2 diabetes. Diabetes Care 32:14-18

60. DeFronzo RA, Okerson T, Viswanathan P, Guan X, Holcombe JH, MacConell L (2008) Effects of exenatide versus sitagliptin on postprandial glucose, insulin and glucagon secretion, gastric emptying, and caloric intake: a randomized, cross-over study. Curr Med Res Opin 24:2943-2952

61. Hansen L, Jobal N, Ekholm E, Cook W, Hirschberg B (2014) Postprandial dynamics of plasma glucose, insulin, and glucagon in patients with type 2 diabetes treated with saxagliptin plus dapagliflozin add-on to metformin therapy. Endocr Pract 20: 1187-1197

62. Ahrén B, Foley JE, Ferrannini E et al (2010) Changes in prandial glucagon levels after a 2-year treatment with vildagliptin or glimepiride in patients with type 2 diabetes inadequately controlled with metformin monotherapy. Diabetes Care 33:730-732

63. Meier JJ, Gallwitz B, Siepmann N et al (2003) Gastric inhibitory polypeptide (GIP) dose-dependently stimulates glucagon secretion in healthy human subjects at euglycaemia. Diabetologia 46: 798-801

64. Vilsbøll T, Krarup T, Madsbad S, Holst JJ (2003) Both GLP-1 and GIP are insulinotropic at basal and postprandial glucose levels and contribute nearly equally to the incretin effect of a meal in healthy subjects. Regul Pept 114:115-121

65. Ravier MA, Rutter GA (2005) Glucose or insulin, but not zinc ions, inhibit glucagon secretion from mouse pancreatic $\alpha$-cells. Diabetes 54:1789-1797

66. Foley JE, Ligueros-Saylan M, He YL (2008) Effect of vildagliptin on glucagon concentration during meals in patients with type 1 diabetes. Horm Metab Res 40:727-730

67. Farngren J, Persson M, Schweizer A, Foley JE, Ahrén B (2012) Vildagliptin reduces glucagon during hyperglycemia and sustains glucagon counterregulation during hypoglycemia in type 1 diabetes. J Clin Endocrinol Metab 97:3799-3806

68. de Heer J, Rasmussen C, Coy DH, Holst JJ (2008) Glucagon-like peptide-1, but not glucose-dependent insulinotropic peptide, inhibits glucagon secretion via somatostatin (receptor subtype 2) in the perfused rat pancreas. Diabetologia 51:2263-2270

69. Farngren J, Persson M, Schweizer A, Foley JE, Ahrén B (2014) Glucagon dynamics during hypoglycemia and food-re-challenge following treatment with vildagliptin in insulin-treated patients with type 2 diabetes. Diabet Obes Metab 16:812-818

70. Christensen M, Vedtofte L, Hot JJ, Vilsbøll T, Knop FK (2011) Glucose-dependent insulinotropic polypeptide: a bifunctional glucose-dependent regulator of glucagon and insulin secretion in humans. Diabetes 60:3103-3109

71. Malmgren S, Ahrén B (2015) DPP-4 inhibition contributes to the prevention of hypoglycaemia through a GIP-glucagon counterregulatory axis in mice. Diabetologia 58:1091-1099

72. Waget A, Cabout C, Masseboeuf M et al (2011) Physiological and pharmacological mechanisms through which the DPP-4 inhibitor sitagliptin regulates glycemia in mice. Endocrinology 152:3018 3029

73. Taylor R, Magnusson I, Rothman DL et al (1996) Direct assessment of liver glycogen storage by $13 \mathrm{C}$ nuclear magnetic resonance spectroscopy and regulation of glucose homeostasis after a mixed meal in normal subjects. J Clin Invest 97:126-132

74. Solis-Herrera C, Triplitt C, Garduno-Garcia Jde J, Adams J, DeFronzo RA, Cersosimo E (2013) Mechanisms of glucose lowering of dipeptidyl peptidase-4 inhibitor sitagliptin when used alone or with metformin in type 2 diabetes: a double-tracer study. Diabetes Care 36:2756-2762

75. Macauley M, Hollingsworth KG, Smith FE et al (2015) Effect of vildagliptin on hepatic steatosis. J Clin Endocrinol Metab 100: $1578-1585$ 
76. Schweizer A, Foley JE, Kothny W, Ahrén B (2013) Clinical evidence and mechanistic basis for vildagliptin's effect in combination with insulin. Vasc Health Risk Manag 9:57-64

77. Liu L, Omar B, Marchetti P, Ahrén B (2014) Dipeptidyl peptidase4 (DPP-4): localization and activity in human and rodent islets. Biochem Biophys Res Comun 453:398-404

78. Marchetti P, Lupi R, Bugliani M et al (2012) A local glucagon-like peptide 1 (GLP-1) system in human pancreatic islets. Diabetologia 55:3262-3272

79. Omar BA, Liehua L, Yamada Y, Seino Y, Marchetti P, Ahrén B (2014) Dipeptidyl peptidase-4 (DPP-4) is expressed in mouse and human islets and its activity is decreased in human islets from type 2 diabetic individuals. Diabetologia 57:1876-1883

80. Shah P, Ardestani A, Dharmadhikari G et al (2013) The DPP-4 inhibitor linagliptin restores beta-cell function and survival in human isolated islets through GLP-1 stabilization. J Clin Endocrinol Metab 98:E1163-E1172

81. Boschmann M, Engeli S, Dobberstein K et al (2009) Dipeptidylpeptidase-IV inhibition augments postprandial lipid mobilization and oxidation in type 2 diabetic patients. J Clin Endocrinol Metab 94:846-852

82. Matikainen N, Mänttäri S, Schweizer A et al (2006) Vildagliptin therapy reduces postprandial intestinal triglyceride-rich lipoprotein particles in patients with type 2 diabetes. Diabetologia 49: 2049-2057

83. Tremblay AJ, Lamarche B, Deacon CF, Weisnagel SJ, Couture P (2011) Effect of sitagliptin therapy on postprandial lipoprotein levels in patients with type 2 diabetes. Diabetes Obes Metab 13: 366-373

84. Eliasson B, Möller-Goede D, Eeg-Olofsson K et al (2012) Lowering of postprandial lipids in individuals with type 2 diabetes treated with alogliptin and/or pioglitazone: a randomised doubleblind placebo-controlled study. Diabetologia 55:915-925

85. Kojima Y, Kaga H, Hayashi S et al (2013) Comparison between sitagliptin and nateglinide on postprandial lipid levels: The STANDARD study. World J Diabetes 4:8-13

86. Xiao C, Dash S, Morgantini C, Patterson BW, Lewis GF (2014) Sitagliptin, a DPP-4 inhibitor, acutely inhibits intestinal lipoprotein particle secretion in healthy humans. Diabetes 63:2394-2401

87. Foley JE, Jordan J (2010) Weight neutrality with the DPP-4 inhibitor, vildagliptin: mechanistic basis and clinical experience. Vasc Health Risk Manag 6:541-548

88. Bunck MC, Cornér A, Eliasson B et al (2010) One-year treatment with exenatide vs. insulin glargine: effects on postprandial glycemia, lipid profiles, and oxidative stress. Atherosclerosis 212:223229

89. Matikainen N, Taskinen MR (2013) The effect of vildagliptin therapy on atherogenic postprandial remnant particles and LDL particle size in subjects with type 2 diabetes. Diabet Med 30:756757

90. Ferre P, Foufelle F (2010) Hepatic steatosis: a role for de novo lipogenesis and the transcription factor SREBP-1c. Diabetes Obes Metab 12(Suppl 2):82-93

91. Vella A, Bock G, Giesler PD et al (2008) The effect of dipeptidyl peptidase-4 inhibition on gastric volume, satiation and enteroendocrine secretion in type 2 diabetes: a double-blind, placebo-controlled crossover study. Clin Endocrinol 69:737-744

92. Aoki K, Kamiyama H, Masuda K et al (2014) Effects of miglitol, vildagliptin, or their combination on serum insulin and peptide YY levels and plasma glucose, cholecystokinin, ghrelin, and obestatin levels. Endocr J 61:249-256

93. Wu T, Bound MJ, Zhao BR et al (2013) Effects of a D-xylose preload with or without sitagliptin on gastric emptying, glucagon-like peptide-1, and postprandial glycemia in type 2 diabetes. Diabetes Care 36:1913-1918

94. Stevens JE, Horowitz M, Deacon CF, Nauck M, Rayner CK, Jones KL (2012) The effects of sitagliptin on gastric emptying in healthy humans - a randomized, controlled study. Aliment Pharmacol Ther 36:379-390

95. Huang CL, Hsu CH, Huang KC, Su HY, Weng SF (2010) Preprandial single oral dose of sitagliptin does not affect circulating ghrelin and gastrin levels in normal subjects. Pharmacology $85: 131-135$

96. Green JB, Bethel MA, Armstrong PW et al (2015) Effect of sitagliptin on cardiovascular outcomes in type 2 diabetes. $\mathrm{N}$ Engl J Med 373:232-242

97. Jensen J, Rustad PI, Kolnes AJ, Lai YC (2011) The role of skeletal muscle glycogen breakdown for regulation of insulin sensitivity by exercise. Front Physiol 2:1-11

98. Derosa G, Carbone A, D'Angelo A et al (2012) A randomized, double-blind, placebo-controlled trial evaluating sitagliptin action on insulin resistance parameters and $\beta$-cell function. Expert Opin Pharmacother 13:2433-2442

99. Derosa G, Carbone A, Franzetti I et al (2012) Effects of a combination of sitagliptin plus metformin vs metformin monotherapy on glycemic control, $\beta$-cell function and insulin resistance in type 2 diabetic patients. Diabetes Res Clin Pract 98:51-60

100. Derosa G, Bonaventura A, Bianchi L et al (2014) Vildagliptin compared to glimepiride on post-prandial lipemia and on insulin resistance in type 2 diabetic patients. Metabolism 63:957-967

101. Taskinen MR, Boren J (2015) New insights into the pathophysiology of dyslipemia in type 2 diabetes. Atherosclerosis 239:483495

102. Blüher M, Schweizer A, Bader G, Foley JE (2014) Changes in body weight after 24 weeks of vildagliptin therapy as a function of fasting glucose levels in patients with type 2 diabetes. Vasc Health Risk Manag 10:661-664 